\title{
Proceeding
}

Supplementary Issue: Rio 2016 Olympic Games First Anniversary Special Edition. Olympic Studies Forum, 4-5 August 2017. Santa Úrsula University. Rio de Janeiro, Brazil

\section{A legacy of knowledge: Meteorology and Olympic and Paralympic Games in Brazil}

\author{
ANTÔNIO SÉRGIO PEREIRA DA SILVA ${ }^{1,2} \unlhd$, CRISTIANO MEIGA BELEM ${ }^{3,4,5}$, JOSÉ FELIPE DA SILVA \\ FARIAS ${ }^{1,2}$ \\ ${ }^{1}$ National Center for Natural Disaster Monitoring and Alerting, CEMADEN, Brazil \\ ${ }^{2}$ Ministry of Science, Technology, Innovation and Communications - MCTIC, Brazil \\ ${ }^{3}$ Federal University of Espirito Santo - UFES, Brazil \\ ${ }^{4}$ Departamento de Linguagens, Cultura e Educação - Centro de Educação - DELC/ CE, Brazil \\ ${ }^{5}$ Programa de Desenvolvimento Científico e Tecnológico Regional - DCR da Fundação de Amparo à \\ Pesquisa e Inovação do Espírito Santo - FAPES, Brazil
}

\begin{abstract}
During the 2016 Olympic and Paralympic Games held in Rio de Janeiro, the Ministry of Science, Technology and Innovation (MCTIC)made available to the Olympic Games organization a meteorological monitoring infrastructure for the preparation of the event and the conduct of the events. Advanced weather systems and supercomputing capabilities coupled with the modeling expertise of scientists have resulted in predictions with a high degree of accuracy. The data, provided with punctuality and precision, contribute information to the search for the best performance of an Olympic athlete, within the environmental climatic conditions of the event. Key words: METEOROLOGY AND SPORT, SPORTS WEATHER SERVICE, METEOROLOGY AND OLYMPIC GAMES, RIO 2016.
\end{abstract}

\section{Cite this article as:}

Pereira da Silva, A.S., Meiga Belem, C. \& Da Silva Farias, J.F. (2018). A legacy of knowledge: Meteorology and Olympic and Paralympic Games in Brazil. Journal of Human Sport and Exercise, 13(1proc), S134-S143. doi:https://doi.org/10.14198/jhse.2018.13.Proc1.11

Corresponding author. National Center for Natural Disaster Monitoring and Alerting, CEMADEN, Brasil.

E-mail: asergio20@hotmail.com

Supplementary Issue: Rio 2016 Olympic Games First Anniversary Special Edition. Olympic Studies Forum, 4-5 August 2017. Santa Úrsula University. Rio de Janeiro, Brazil.

JOURNAL OF HUMAN SPORT \& EXERCISE ISSN 1988-5202

(C) Faculty of Education. University of Alicante

doi:10.14198/jhse.2018.13.Proc1.11

S134 | 2018 | Proc1 | VOLUME 13

(C) 2018 University of Alicante 


\section{Um legado de conhecimento: A meteorologia e Jogos Olímpicos e Paralímpicos no Brasil}

\section{RESUMO}

Durante os Jogos Olímpicos e Paralímpicos de 2016 realizados no Rio de Janeiro, o Ministério da Ciência, Tecnologia e Inovação (MCTI) colocou à disposição da organização dos Jogos Olímpicos uma infraestrutura de monitoramento meteorológico para a preparação do evento e realização das provas. Sistemas meteorológicos avançados e recursos de supercomputação somados à expertise de modelagem dos cientistas resultaram em previsões com alto índice de acerto. Os dados, fornecidos com pontualidade e precisão, contribuem com informações para a busca do melhor desempenho de um atleta olímpico, dentro das condições climático-ambientais da prova. Palavras-chave: METEOROLOGIA E ESPORTE; SERVIÇO METEOROLÓGICO ESPORTIVO; METEOROLOGIA E JOGOS OLÍMPICOS, RIO 2016. 


\section{INTRODUÇÃO}

Desde 1896, em Atenas, até os dias atuais, os Jogos Olímpicos de Verão ou Olimpíadas de Verão representam um conjunto de provas esportivas de caráter mundial, disputadas de 4 em 4 anos em cidadessedes, que se candidatam com antecedência, junto ao Comitê Olímpico Internacional (COI), (Hellenic National Meteorological Service, 2004).

Podem participar dessas provas qualquer atleta ou equipe representando país filiado ao COI, desde que se obedeça às normas estabelecidas pelos regulamentos olímpicos e pelas leis que regem os respectivos esportes. A cada país organizador é dado o direito de incluir 2 esportes não olímpicos no programa oficial.

Os Jogos Olímpicos da Era Moderna - que começaram em 1896, são na verdade, uma nova versão dos festivais esportivos que os gregos realizavam, também de 4 em 4 anos, na antiga Élida em honra de Zeus e de outros deuses que habitavam o Olimpo. Dessa versão modernizada resultaram outras, inclusive a dos Jogos Olímpicos de Inverno.

Os jogos Olímpicos têm como característica principal ser um evento multiesportivo, que significa competições que envolvem vários esportes e modalidades desportivas que são disputadas juntas.

Os XXXI Jogos Olímpicos de Verão foram realizados no Rio de Janeiro em agosto de 2016. O lema dos Jogos foi "Viva sua paixão". Participaram cerca de 10.700 atletas de 205 nações e 2 delegações especiais (Atletas Olímpicos Independentes e Atletas Olímpicos Refugiados). Ao todo foram disputadas 42 modalidades esportivas, 306 provas, duas a mais (Rúgbi de Sete e Golfe) do que nos Jogos Olímpicos de 2012.

As 42 modalidades de 33 esportes disputadas na Olimpíada do Rio de Janeiro de 2016 foram respectivamente em ordem alfabética: - atletismo, badminton, basquetebol, boxe, canoagem (slalom e velocidade), ciclismo (BMX, estrada, pista, mountain bike), esgrima, futebol, ginástica, golfe, levantamento de peso (halterofilismo), hipismo (adestramento, concurso completo de equitação e salto), hóquei sobre grama, judô, luta olímpica (livre e Greco romana), maratona aquática, natação, nado sincronizado, saltos ornamentais, pólo aquático, pentatlo moderno, remo, rúgbi, taekwondo, tiro com arco, tiro esportivo, tênis, tênis de mesa, triatlo, vela, voleibol e vôlei de praia.

\section{Momento Histórico}

Este artigo busca relatar uma história inédita no país. A participação de uma equipe de meteorologistas (MCTIC, 2016), oriundos de vários órgãos do governo federal, como Centro Nacional de Monitoramento e Alertas de Desastres Naturais (Cemaden),Instituto Estadual do Ambiente (INEA), Marinha do Brasil, Departamento de Controle do Espaço Aéreo (DECEA), Centro de Previsão e Estudos Climáticos (CPTEC) e Instituto Nacional de Pesquisas Espacias (INPE), que muito trabalharam para fortalecer o binômio segurança e diversão ao longo da realização dos jogos olímpicos e paralímpicos acontecidos na cidade do Rio de Janeiro. 


\section{EQUIPE DO SERVIÇO METEOROLÓGICO ESPORTIVO - SME}

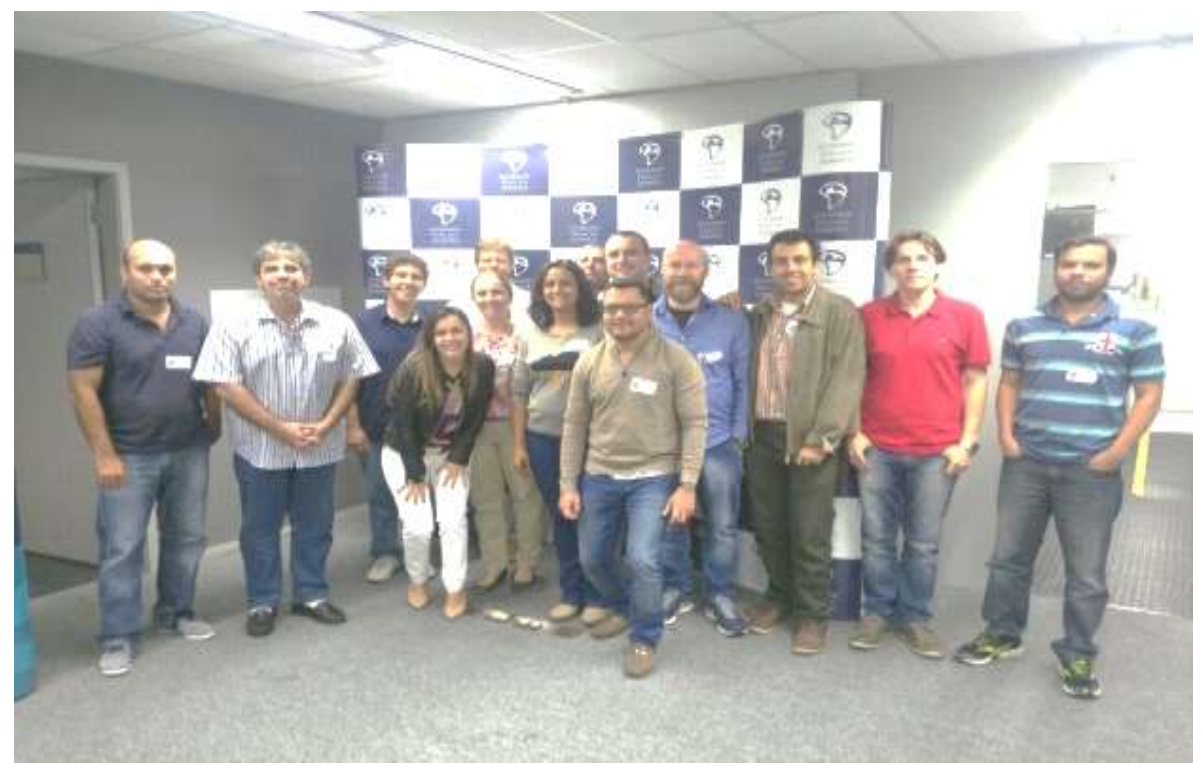

Figura 1. Foto da equipe de Meteorologia em reunião na sede da Autoridade Pública Olímpica no Rio de Janeiro. Fonte: arquivo pessoal do autor.

Foram dias inesqueciveis. Desde a ida a Cidade do Samba para buscar os uniformes. Após algumas horas de espera na fila, a equipe chegou ao local que realizava a triagem do pessoal. Mostramosa identidade $e$ explicamosque fomos escalados para fazer a previsão do tempo ao longo das competições. Para total surpresa os nomes dos membros equipenão constavam da relação das pessoas que trabalhariam nos jogos. Foi necessário passar para outro local e realizar outra triagem, desta vez para identificar se poderia participar ou não do trabalho, pois não havia nenhum documento que informasse a presença de meteorologista, ou mesmo o que era e o quê este faria. Aguardamos durante mais um tempo e, finalmente, apareceu uma jovem informando que a Autoridade Pública Olímpica (APO), ainda não havia informado a quantidade de meteorologistas e em qual local seria efetuado o trabalho. Esperamos mais um pouco e fomos encaminhados ao local para pegar os uniformes e credenciais, acompanhado de um pedido de desculpas e informando que achavam muito interessante ter profissionais do tempo trabalhando nos jogos.

Uma vez solucionado esse problema, os demais colegas que chegaram foram devidamente encaminhados, em tempo recorde, para receberem seus uniformes. A equipe foi escalada para ficar no Main Operation Center (MOC) e alocada em pequeno espaço cedido pelo gerente do MOC, em duas mesas com três cadeiras. Montou-se uma escala para que se pudesse chegar a tempo do primeiro briefing da manhã que se iniciava às $06 \mathrm{~h} 15 \mathrm{~min}$, colocando a previsão para o dia e a possibilidade de ter avisos importantes que afetariam alguma competição. 


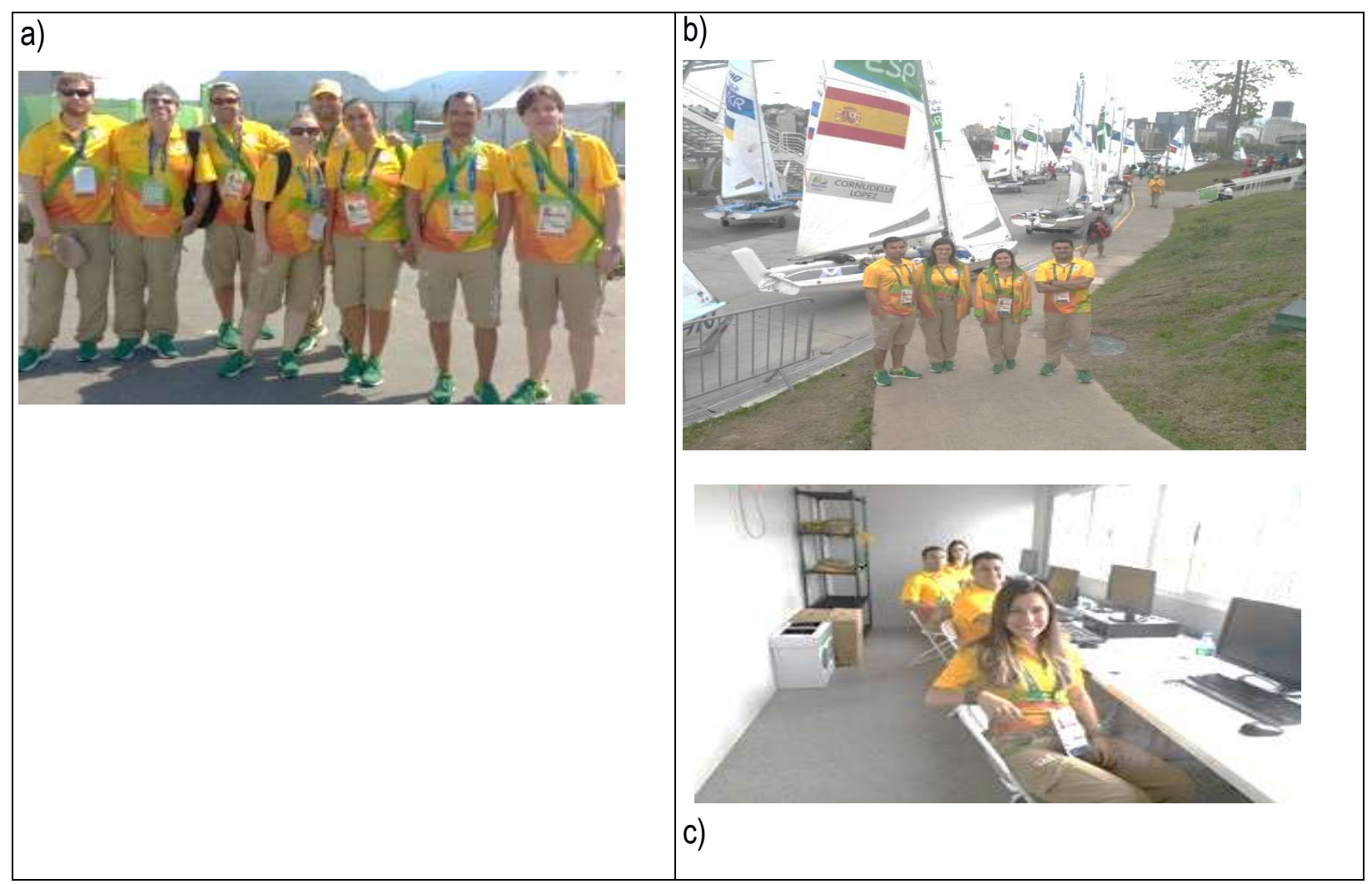

Quadro 1. Imagens das equipes de meteorologistas nos locais de provas. a) Equipe do Centro Principal de Operação - MOC. b) Equipe da Vela - Marina da Glória. C) Equipe de Remo e Canoagem Lagoa Rodrigo de Freitas. Fonte: arquivo pessoal do autor

\section{DESAFIOS DO SISTEMA METEOROLÓGICO ESPORTIVO}

\section{Previsão de Tempo}

Os quatro Clusters escolhidos para agrupar os locais onde seriam realizados os jogos foram classificados pelos meteorologistas como um excelente desafio. Dois locais, Barra da Tijuca e Copacabana, sofriam a influência direta do oceano. Enquanto os outros dois possuíam características próprias. Maracanã, apesar do intenso trânsito existente no local, havia uma singela influência da baía da Guanabara. Já em Deodoro, as condições não deixavam dúvida, seria uma localidade com dificuldades, pois as temperaturas estavam altas (Belem, 2013) e a umidade baixa. Este local seria um excelente desafio para os meteorologistas, pois havia os cavalos que eram bastante sensíveis as variações de umidade relativa do ar, caracterizado através do "estresse térmico". 


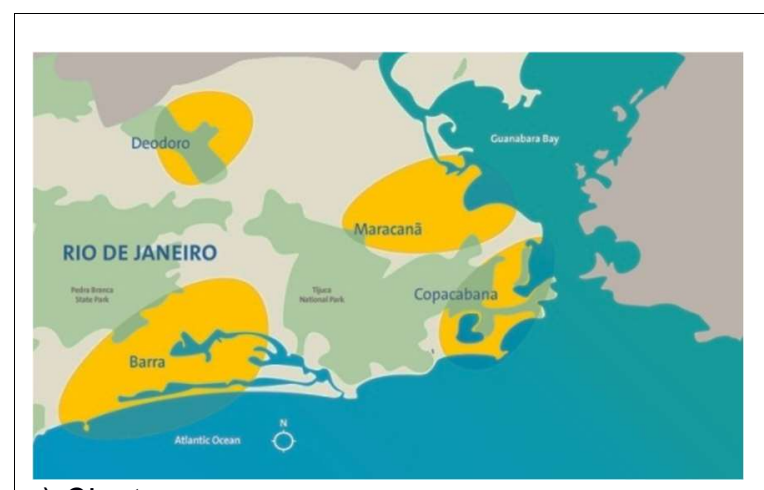

a) Clusters

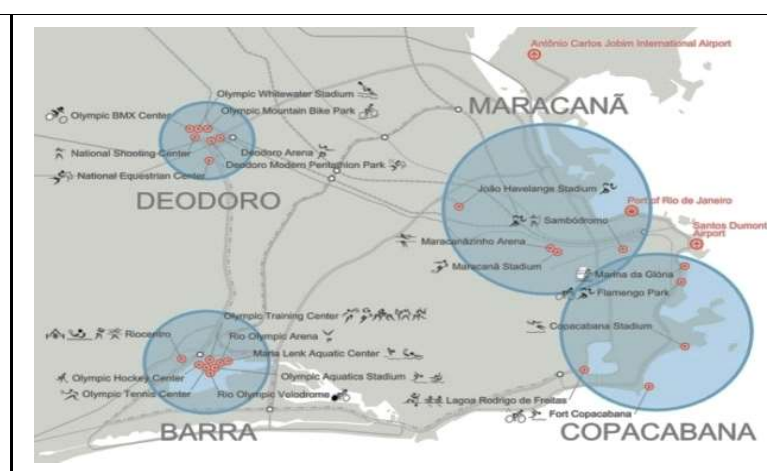

Locais de competição

Quadro 2. Imagem dos Clusters e Venues a) Clusters para análises meteorológicas b) Venues - Localização das competições. Fonte: Site da Rio 2016 - Comitê Olímpico Brasileiro

Em relação aos Venues não haveria problemas para a previsão. As informações quando passadas para 0 Cluster serviriam para todos os locais de competição. Dificilmente, dentro de um Cluster haveria variação das condições meteorológicas para uma só Venue.

Um exemplo foi a ocorrência de temperaturas elevadas para competições em locais abertos, principalmente em Deodoro, mas a previsão não especificava este ou aquele venue com competição em área exposta a maior incidência de infra-vermelho.

\section{Plataforma Olympia}

Nesta plataforma criada com a participação de todos os órgãos envolvidos, foram colocadas todas as informações necessárias para se ler, ver e obter os dados brutos e alguns já trabalhados para a feitura das previsõesdo Instituto Nacional de Meterorologia [INMET] (2015). Todos os dados observacionais coletados pelas estações meteorológicas de superfície e altitude disponíveis no Rio de Janeiro e em estados circunvizinhos foram disponibilizados nesta plataforma. Imagens de satélites meteorológicos, radares, informações de aeroportos como Metar e Terminal Aerodrome Forescast (TAF), descargas elétricas, indicativos de ventos fortes, enfim, uma grande quantidade de dados disponíveis nos órgãos que oferecem serviço de Meteorologia no país e também de órgãos internacionais foram inseridos na Plataforma Olympia. Muitos meteorologistas não estavam acostumados a trabalhar com uma gama de dados desta magnitude, porém foi muito rápida a adaptação. 


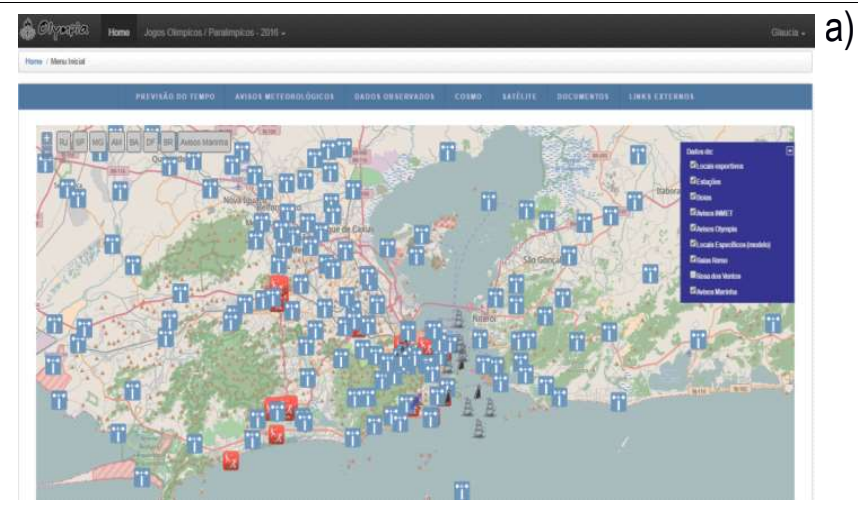

Plataforma Olympia

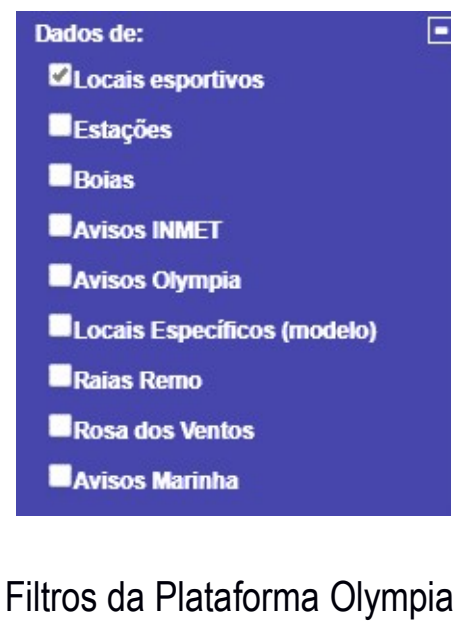

b) Filtros da Plataforma Olympia

Quadro 3. Imagem da Plataforma Olympia a) Plataforma Olympia com Estações Meteorológicas de Superfície e Locais Esportivos b) Destaque para as informações da Plataforma Olympia Fonte: Site do Serviço Meteorológico Esportivo (SME), Instituto Nacional de Meteorologia (INMET).

A Olympia procurou alocar as informações usadas pela equipe nas áreas de sua responsabilidade. Se na Marina da Glória ocorressem ventos moderados ou fortes, colocando em risco a competição, estas informações seriam sinalizadas na plataforma.

Um legado do conhecimento deixado pelos jogos foram as informações inseridas na Plataforma Olympia. Muito importantes os dados obtidos pelas três boias colocadas pela Diretoria de Hidrografia e Navegação (DHN), da Marinha do Brasil. Assim, quando a equipe da Vela passava um aviso de vento para a área de sua responsabilidade, os demais meteorologistas ficavam atentos, pois este fenômeno poderia afetar as atividades do continente.

Utilizou-se ainda o Sonic Detection and Ranging (SODAR), aparelho em estágio experimental no aeródromo do Rio de Janeiro - Santos Dumont, responsável pela informação de mudança de intensidade e direção do vento em alturas diferentes. Este instrumento é utilizado para detectar a ocorrência da perigosa tesoura de vento - Wind shear, responsável por acidentes com aeronaves.

Todas as previsões foram realizadas na Olympia. Foram acompanhadas as competições que começavam pela manhã até a última da noite. As arenas de futebol recebiam informações para o treinamento, antes e durante 0 jogo. Caso houvesse alguma mudança significativa, passava-se um aviso. 0 monitoramento foi efetuado durante os horários dos jogos e a equipe de meteorologistas participou de todos osbriefing.

$\mathrm{Na}$ Plataforma havia uma página para consulta de usuários sobre as condições meteorológicas para cada um dos 4 clusters, onde eram inseridos os valores de temperatura e previsão de alguma ocorrência significativa, e que podiam se acessados mediante a instalação de um aplicativo para celular. A atualização era realizada duas vezes ao dia e, em caso de mudança brusca a página era acessada e modificada.

\section{Monitoramento}

O monitoramento foi feito ao longo das duas competições, sem interrupção. Mesmo com as condições meteorológicas favoráveis para que os jogos pudessem ser realizados, os meteorologistas acompanhavam os sistemas, as condições de umidade e calor. Preocupava saber se nas competições ao ar livre a 
intensidade do vento, a pressão, o efeito da brisa atrapalhariam a realização ou mesmo o adiamento dos eventos.

O monitoramento para as arenas de futebol era feito até o início do segundo tempo. Mesmo que a previsão confirmasse condições ideais para a realização do evento, ficava-se aguardando a possibilidade de ocorrer alguma mudança, pois as arenas estavam espalhadas pelo país e em algumas regiões (Manaus) o regime de chuva era mais intenso.

Para que se pudesse concretizar este monitoramento, mantendo o padrão de qualidade de trabalho, quando houvesse, por parte dos meteorologistas, a conclusão de que haveria uma mudança significativa das condições meteorológicas, fazia-se uso dos avisos meteorológicos.

Estes avisos seguiam uma ordem de intensidade do evento, começando com o amarelo, passando a laranja e terminando em vermelho. Se o sistema estivesse com bastante atividade já poderia entrar lançar o aviso vermelho, que representava condições meteorológicas mais extremas, podendo adiar ou mesmo cancelar um evento.

Os avisos ficavam armazenados no sistema para efeito de comprovação ou necessidade de se usar como documento para justificar a ocorrência de um fenômeno mais intenso. Ao longo da competição foram solicitadas, por vezes, cópias dos avisos para outros órgãos envolvidos nos Jogos.

Após alguns corridos dias e muito trabalho, começou-se a atender solicitações de outras gerências. Os setores do transporte de atletas, de energia elétrica, de segurança, entre outros, consultavam para saber se haveria chuva, vento, calor e outros parâmetros não menos importantes. Algumas vezes os avisos foram repetidos durante a madrugada, pois havia previsão de continuidade dos fenômenos ao longo da noite até ao amanhecer. No primeiro briefing da manhã atualizava-se o aviso. Outras vezes o mesmo era cancelado ao chegar ao MOC.
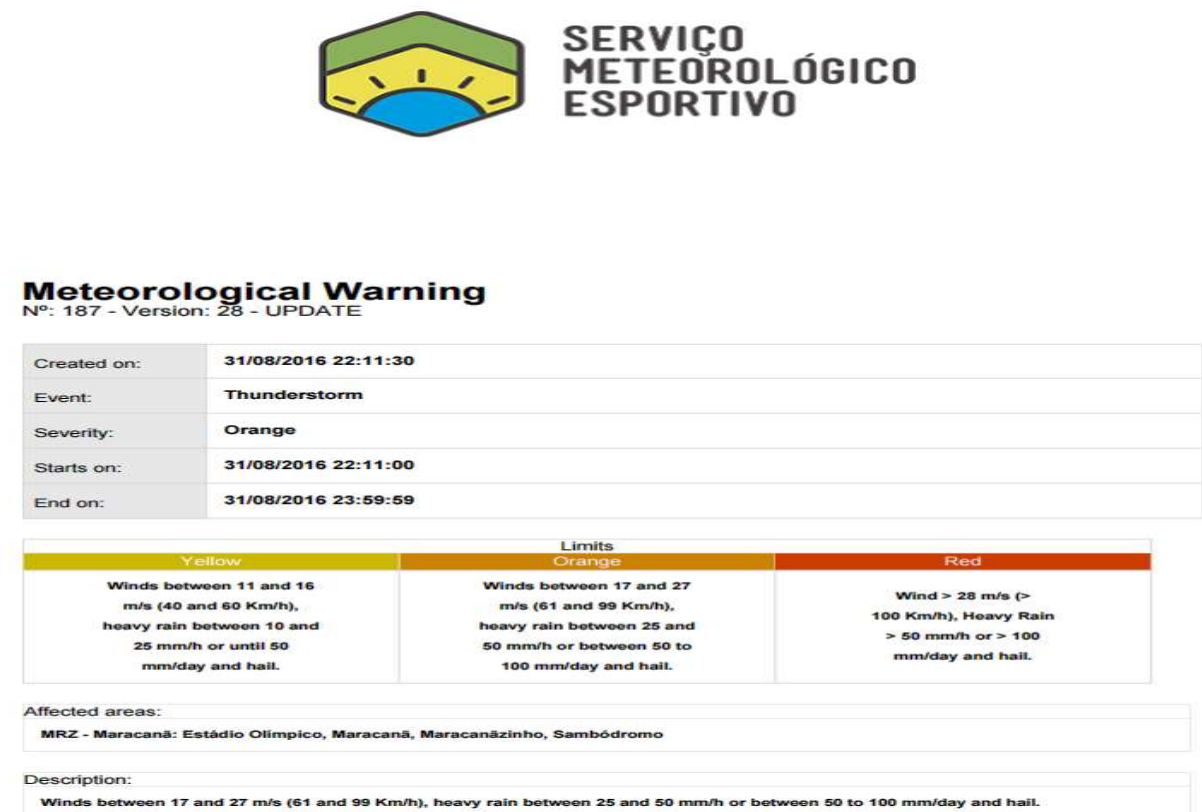

Figura 2. Exemplo de aviso meteorológico laranja - Site do Serviço Meteorológico Esportivo (SME) Instituto Nacional de Meteorologia (INMET) 


\section{RESULTADOS}

A tabela abaixo demostra os números alcançados ao longo dos meses pelos meteorologistas que estavam no MOC e ficaram à disposição dos da organização dos Jogos Olímpicos realizados no Rio de Janeiro em 2016. Os meteorologistas mantiveram uma interação significativa com os organizadores, participantes, contratados e até mesmo tomadores de decisão (gerentes).

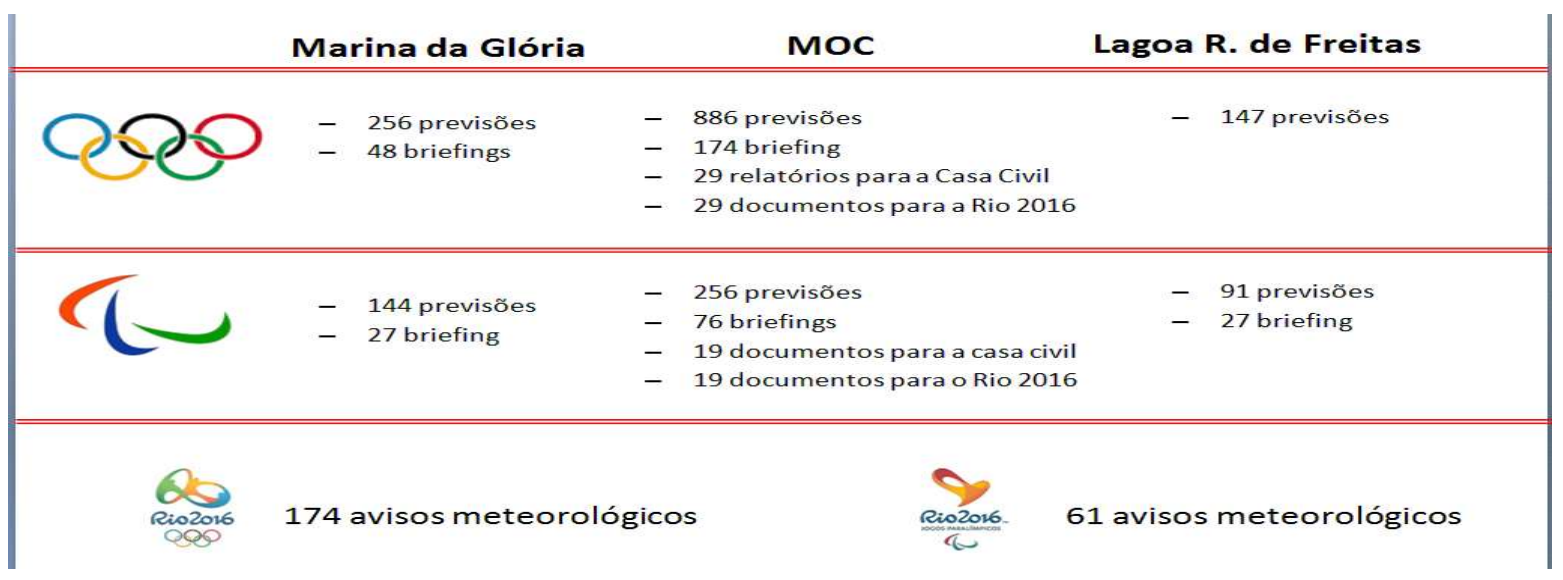

Tabela1. Tabela de resultados. Fonte: www.inmet.gov.br - Instituto Nacional de Meteorologia

Os números mostram o legado deixado para a equipe de meteorologistas, que foi, sem dúvida alguma, 0 conhecimento. Algumas modalidades esportivas são expressamente dependentes das condições meteorológicas reinantes (Belem, 2013) no momento em que ocorrem. Os meteorologistas não foram pegos de surpresa, pois vieram orientados de que suas informações seriam importantes para a maioria dos atletas. Sabe-se, inclusive, que há equipes que trazem seus meteorologistas que ao receberam os dados brutos transformam em informação privilegiada para o participante da competição.

No MOC foram feitas 886 previsões, participou-se de 174 briefinge informou-se a maioria das mudanças significativas que poderiam ocorrer. Em algumas destas reuniões o grupo de meteorologia não era chamado para participar, principalmente quando havia previsão de ocorrer algum problema.

Nos jogos Paralímpicos não foi diferente. Continuou-se mantendo o mesmo "modus operandi", participando dos briefing, colocando as mudanças significativas e passando os avisos quando necessários.

\section{CONSIDERAÇÕES FINAIS}

Os meteorologistas chegaram antes do início dos jogos e o grupo começou a trabalhar na previsão do tempo para a cerimônia de abertura. Com a aproximação de uma frente fria de fraca intensidade, no primeiro briefing, colocou-se a possibilidade da festa ter um convidado indesejado, ou seja, a chuva. Foi um impacto muito negativo, porém, a equipe informou que estava ali para ajudar, pois diante desta informação as providências deveriam ser tomadas. Infelizmente, houve chuva na abertura dos jogos olímpicos e, salvo engano nos paralímpicos também. Ao longo da olimpíada e da paralimpíada manteve-se o compromisso de informar quaisquer anomalias que pudessem interferir no bom andamento da competição. 
Quando se fala em legado dos Jogos não se tem dúvida alguma de que este foi o conhecimento. Desde 0 início nas reuniões da Autoridade Pública Olímpica e, diante da quantidade de necessidades de informações para o desempenho das solicitações, verificou-se que esse desafio só poderia ser alcançado mediante aos conhecimentos multidisciplinares de todos órgãos envolvidos, para atender aos pedidos do Comitê Olímpico Brasileiro.

\section{CONCLUSÃO}

Durante os Jogos Olímpicos e Paralímpicos de 2016 realizados no Rio de Janeiro, o MCTIC colocou à disposição da organização dos Jogos Olímpicos uma infraestrutura de monitoramento meteorológico para a preparação do evento e realização das provas.

O legado dos Jogos Olímpicos necessita ser estudado e os conhecimentos gerados devem ser compartilhados dentro das instituições do sistema olímpico, pesquisadores, acessível ao público e a profissionais das áreas envolvidas. Assim sendo, a disponibilização e divulgação dos avanços do conhecimento com os Jogos Olímpicos no Brasil deveria ser considerada como política governamental.

Nesse sentido, ratifica-se o entendimento DaCosta (2015) de que os estudos e geração do conhecimento fazem parte do legado e confirmam que o futuro dos Jogos Olímpicos é parte de uma pesquisa voltada para a herança do conhecimento.

\section{REFERENCES}

Belem, C.M. (2013). Temperatura, ambiente e população: Mudanças urbanas e fatores climáticos nos sítios competitivos dos Jogos Rio 2016 na cidade do Rio de Janeiro. In C.M. Belem (2014). A aplicação das geotecnologias na gestão do esporte: um olhar sobre os megaeventos esportivos na cidade do Rio de Janeiro. Tese de doutorado, Universidade Gama Filho, Rio de Janeiro, RJ, Brasil.

DaCosta, L. P., Oliveira, A.F.S.de, Taffarel, C.N.Z. \& Belem, C.M. (2015). Legacy as knowledge. In V. Viehoff \& G. Taylor (Orgs.). Mega-Event Cities: Urban legacies of global sports events (pp.153-162). London and New York: Routledge.

Hellenic National Meteorological Service. (2005, november). Weather support for Athens Olympic Games 2004 using Web Based technology. 10th Workshop on Meteorological Operational Systems. Retrieved july 27, 2017, from https://www.ecmwf.int/sites/defaultffiles/elibrary/2005/15764-weathersupport-athens-olympic-games-2004-using-web-based-technology.pdf

National Institute of Meteorology (2015, janeiro). Weather information for the Olympic and Paralympic Games in Rio de Janeiro. Retrieved july 27, 2017, from HYPERLINK https://inside.fei.org/system/files/RIO\%20Weather

\section{@) $\odot \Theta \Theta$}

This title is licensed under a Creative Commons Attribution-NonCommercial-NoDerivs 3.0 Unported License. 